\title{
Mild-to-moderate functional tricuspid regurgitation in patients undergoing mitral valve surgery
}

\author{
Sun Kyun Ro, MD, Joon Bum Kim, MD, Sung Ho Jung, MD, Suk Jung Choo, MD, \\ Cheol Hyun Chung, MD, and Jae Won Lee, MD
}

\begin{abstract}
Objective: The decision to repair mild-to-moderate functional tricuspid regurgitation (TR) during mitral valve surgery remains controversial. We evaluated the effects of tricuspid valve (TV) repair for functional mild-tomoderate TR during mitral valve surgery.
\end{abstract}

\begin{abstract}
Methods: We enrolled 959 patients with mild-to-moderate functional TR who underwent mitral valve surgery with (repair group $n=431$ ) or without (control group $n=528$ ) concomitant TV repair from January 1994 to September 2010.

Results: There were no significant differences in early mortality or major morbidity rates. Median follow-up was 64.8 months (range, 0.03-203.6 months). After adjustment for baseline characteristics using a propensity score adjustment model, the repair group had similar risks for TV reoperation (hazard ratio [HR], 0.46; 95\% confidence interval $[\mathrm{CI}], 0.10-2.07 ; P=.31$ ); congestive heart failure (HR, 1.12; 95\% CI, 0.37-3.36; $P=.84)$; death (HR, $1.41 ; 95 \% \mathrm{CI}, 0.82-2.42 ; P=.22)$; and the composite of death, TV reoperation, and congestive heart failure (HR, 1.24; $95 \% \mathrm{CI}, 0.76-2.03 ; P=.39$ ) compared with the control group. On multivariate Cox-regression analysis, old age, atrial fibrillation without a Maze procedure, diabetes mellitus, chronic renal failure, poor left ventricular ejection fraction, and redo surgery emerged as significant independent risk factors for the composite outcome of death, TV reoperation, and congestive heart failure.

Conclusions: Early or late clinical benefits of concomitant TV repair for mild-to-moderate TR during mitral valve surgery were uncertain through a long-term follow-up of 959 patients. Several preoperative factors and the performance of Maze procedure for AF seem to be more important than TV repair in overall clinical outcomes. (J Thorac Cardiovasc Surg 2013;146:1092-7)
\end{abstract}

Functional tricuspid regurgitation (TR) is common in patients with longstanding left heart valve disease. ${ }^{1}$ Although functional TR might improve after correction of left heart lesions, ${ }^{2}$ uncorrected significant TR is reported to progress in almost half of patients, ${ }^{3}$ and increase postoperative mortality and morbidity. ${ }^{4}$ The significance of overlooked functional TR was recently affirmed and several studies reported on concomitant repair of functional TR. Severe TR in patients with mitral valve (MV) disease requiring MV surgery is a definite indication (Class I) for concurrent tricuspid valve (TV) repair. ${ }^{5,6}$ However, the decision to repair lesser degree of functional TR during MV surgery is not well defined, and the optimal strategy for treatment of functional TR remains controversial.

\footnotetext{
From the Department of Thoracic and Cardiovascular Surgery, Asan Medical Center, University of Ulsan College of Medicine, Seoul, South Korea.

Disclosures: Authors have nothing to disclose with regard to commercial support.

Received for publication Feb 14, 2012; revisions received June 28, 2012; accepted for publication July 31, 2012; available ahead of print Sept 3, 2012.

Address for reprints: Jae Won Lee, MD, Department of Thoracic and Cardiovascular Surgery, Asan Medical Center, University of Ulsan College of Medicine, 388-1 Pungnap-dong Songpa-gu, Seoul 138-736, South Korea (E-mail: jwlee@amc. seoul.kr).

$0022-5223 / \$ 36.00$

Copyright (c) 2013 by The American Association for Thoracic Surgery

http://dx.doi.org/10.1016/j.jtcvs.2012.07.100
}

Therefore, we reviewed patients with mild-to-moderate TR who underwent left heart valve surgery to determine how TV repair affects the clinical and echocardiographic outcomes and to identify factors associated with mortality, $\mathrm{TV}$ reoperation, or congestive heart failure (CHF) after MV surgery.

\section{PATIENTS AND METHODS \\ Study Population}

From January 1994 to September $2010,5,634$ patients aged $\geq 18$ years underwent surgery for left heart valve disease at Asan Medical Center, Seoul, South Korea. Among these, patients with coronary disease requiring intervention $(\mathrm{n}=612)$ were excluded. Of the remaining 5022 patients, 1116 patients had mild-to-moderate functional TR on preoperative echocardiogram and 959 patients were finally enrolled after excluding patients with nonmitral pathology $(\mathrm{n}=157)$. Functional TR was defined as TR without definite organic leaflet or subvalvular deformities, such as TV prolapse, rheumatic involvement, infective endocarditis, or Ebstein anomaly. Of the 959 with mild-to-moderate functional TR, 431 patients underwent concomitant TV repair (repair group) and 528 patients did not (control group).

This study was approved by our institutional Ethics Committee/Review Board, which waived the requirement for informed patient consent because of the retrospective nature of this study.

\section{Echocardiographic Evaluation}

Two-dimensional echocardiography and Doppler color-flow imaging were performed on all patients using a Hewlett-Packard Sonos 2500 or 


$$
\begin{aligned}
& \text { Abbreviations and Acronyms } \\
& \text { AF }=\text { atrial fibrillation } \\
& \text { CHF }=\text { congestive heart failure } \\
& \text { LVEF }=\text { left ventricular ejection fraction } \\
& \text { MV }=\text { mitral valve } \\
& \text { TR }=\text { tricuspid regurgitation } \\
& \text { TV }=\text { tricuspid valve }
\end{aligned}
$$

5500 imaging system equipped with a 2.5-MHz transducer (Hewlett-Packard, Andover, Mass). All patients underwent transthoracic echocardiographic evaluation before operation.

The degree of TR was evaluated using the apical 4-chamber view, and graded as mild, moderate, or severe when the distal jet area was $<5 \mathrm{~cm}^{2}$, 5 to $10 \mathrm{~cm}^{2}$, or $>10 \mathrm{~cm}^{2}$, respectively. ${ }^{7}$ The peak systolic TR jet velocity measured by continuous-wave Doppler was used to calculate the TR peak pressure gradient using the simplified Bernoulli equation (pressure gradient $=4 \times$ velocity $^{2}$ ) to estimate the peak systolic pulmonary artery pressure.

\section{Surgical Procedures}

The decision to perform TV repair was affected by the degree of TR, tricuspid annular dimension, left ventricular function, combined procedures, and the presence of atrial fibrillation; but was ultimately at the discretion of the attending surgeon. Because TV annular dimension was not routinely measured pre- or intraoperatively, annular size was not an indispensable indicator for combination of TV repair. In cases of TV repair, TR was repaired by suture annuloplasty, ring annuloplasty, or both, and surgical techniques were determined based on each surgeon's preference.

Minimally invasive cardiac surgeries included right minithoracotomy, upper sternotomy, and lower sternotomy, and Maze procedures were performed by a modified Cox-Maze III technique using cryoablation or a microwave source.

\section{Follow-up}

Data were obtained from medical charts during regular visits to the outpatient clinic or by telephone contact. Vital status data were acquired from the Korean National Registry of vital statistics. Operative mortality was defined as death within 30 days after surgery.

The primary end points of this study included all-cause mortality, TV reoperation, and re-admission for CHF. The secondary end points were the composite of valve-related complications, which included thromboembolic events, anticoagulation-related hemorrhage, reoperation for leftsided valves, and infective endocarditis. Readmission for CHF was defined as an unplanned and urgent admission for management of CHF. Anticoagulation-related hemorrhage was defined as any requirement for transfusion, unplanned admission, or a hemostatic intervention associated with prolonged prothrombin time.

Postoperative TR grade and left ventricular ejection fraction (LVEF) were obtained from the final postoperative echocardiogram obtained after 6 months in patients who survived $>6$ months.

\section{Statistical Analysis}

Categorical variables are presented as numbers and percentages and were compared using the $\chi^{2}$ and Fisher exact tests. Continuous variables are expressed as mean \pm standard deviation and were compared using

\begin{tabular}{|c|c|c|c|}
\hline & $\begin{array}{l}\text { Repair } \\
\text { group }\end{array}$ & $\begin{array}{l}\text { Nonrepair } \\
\text { group }\end{array}$ & $\boldsymbol{P}$ \\
\hline No. of patients & 431 & 528 & \\
\hline Age (y) & $53.3 \pm 13.2$ & $49.1 \pm 12.3$ & $<.001$ \\
\hline Man & $152(35.3)$ & $228(43.2)$ & .013 \\
\hline Diabetes mellitus & $30(7.0)$ & $29(5.5)$ & .35 \\
\hline Hypertension & $59(13.7)$ & $77(14.6)$ & .69 \\
\hline Chronic renal failure & $3(0.7)$ & $2(0.4)$ & .66 \\
\hline Redo open heart surgery & $26(6.0)$ & $7(1.3)$ & $<.001$ \\
\hline Atrial fibrillation & $303(70.3)$ & $288(54.5)$ & $<.001$ \\
\hline Maze procedure & $194(45.0)$ & $185(35.0)$ & $<.001$ \\
\hline History of thromboembolic events & $32(7.4)$ & $46(8.7)$ & .47 \\
\hline Stroke & $29(6.7)$ & $38(7.2)$ & .78 \\
\hline Other thromboembolic events & $3(0.7)$ & $9(1.7)$ & .24 \\
\hline \multicolumn{4}{|l|}{ Mitral valve pathology } \\
\hline Mitral regurgitation & $244(56.6)$ & $260(49.2)$ & .073 \\
\hline Mitral stenosis & $129(29.9)$ & $182(34.5)$ & .073 \\
\hline Mixed lesion & $58(13.5)$ & $86(16.3)$ & .073 \\
\hline \multicolumn{4}{|l|}{ Tricuspid regurgitation } \\
\hline Mild & $150(34.8)$ & $495(93.8)$ & $<.001$ \\
\hline Moderate & $281(65.2)$ & $33(6.3)$ & $<.001$ \\
\hline LV ejection fraction $(\%)$ & $55.9 \pm 9.7$ & $58.3 \pm 9.0$ & $<.001$ \\
\hline LV end-systolic dimension (mm) & $39.0 \pm 8.1$ & $38.0 \pm 6.8$ & .044 \\
\hline LV end-diastolic dimension (mm) & $56.6 \pm 9.7$ & $56.8 \pm 8.6$ & .81 \\
\hline Left atrial dimension $(\mathrm{mm})$ & $60.2 \pm 11.9$ & $56.7 \pm 10.1$ & $<.001$ \\
\hline $\begin{array}{l}\text { Trans TV pressure gradient } \\
\quad(\mathrm{mm} \mathrm{Hg})\end{array}$ & $45.0 \pm 17.3$ & $35.5 \pm 14.7$ & $<.001$ \\
\hline \multicolumn{4}{|l|}{ Surgery type } \\
\hline MVP & $184(42.7)$ & $222(42.0)$ & .84 \\
\hline MVR & $247(57.3)$ & $306(58.0)$ & .84 \\
\hline MICS & $87(20.2)$ & $128(24.2)$ & .13 \\
\hline
\end{tabular}
the $t$ test or the Mann-Whitney $U$ test, as appropriate. To adjust for differences in the baseline patient characteristics between groups, propensity score analysis was performed. The propensity scores were estimated without regard to outcome variables through binary logistic regression analysis incorporating 17 prespecified covariates listed in Table 1. The
TABLE 1. Baseline and operative characteristics

Data are presented as mean \pm standard deviation or number (\%). $L V$, Left ventricular; $T V$, tricuspid valve; $M V P$, mitral valve repair; $M V R$, mitral valve replacement; $M I C S$, minimally invasive cardiac surgery.

discrimination and calibration ability of the propensity score model was assessed using the $C$ statistic and the Hosmer-Lemeshow statistic. The model was well calibrated (Hosmer-Lemeshow test $P=.707$ ) with reasonable discrimination ( $C$ statistic, 0.880 ). The hazard of concomitant TV repair affecting the clinical outcomes compared with nonrepair was analyzed using the Cox regression model without and with adjustment by propensity scores. Cumulative incidence rates of individual and composite outcomes were also estimated using Cox regression model. Multivariable risk factors for the composite of death, TV reoperation, and CHF requiring readmission were obtained using the Cox proportional hazards model. Variables with a $P$ value $\leq .20$ on univariate analyses were candidates for the multivariable models. Multivariable analyses involved a backward elimination technique, and only variables with a $P$ value $<.10$ were used in the final model.

To compare postoperative echocardiographic outcomes between the groups, propensity score matching was performed. In patients who had follow-up echocardiogram, propensity scores were re-estimated (Hosmer-Lemeshow test $P=.350 ; C$ statistic, 0.877). To develop the propensity score-matched pairs without replacement (a 1:1 match), the Greedy 5 to 1 digit match algorithm was used. ${ }^{8,9}$ After propensity score matching, the baseline covariates were compared between the groups using the paired $t$ test or the Wilcoxon signed-rank test for continuous variables and the McNemar test or marginal homogeneity test for categorical variables. SPSS software version 18.0 (IBM, Armonk, NY) was used for statistical analyses. 
TABLE 2. Operative outcomes

\begin{tabular}{lccc}
\hline & $\begin{array}{c}\text { Repair } \\
\text { group }\end{array}$ & $\begin{array}{c}\text { Nonrepair } \\
\text { group }\end{array}$ & $\boldsymbol{P}$ \\
\hline Early outcomes & & & \\
Operative mortality & $7(1.6)$ & $3(0.6)$ & .12 \\
Early complications & $67(15.5)$ & $71(13.4)$ & .36 \\
$\quad$ Sternal bleeding & $30(7.0)$ & $23(4.4)$ & .079 \\
$\quad$ Pericardial effusion & $10(2.3)$ & $19(3.6)$ & .25 \\
$\quad$ Wound problem & $6(1.4)$ & $11(2.1)$ & .47 \\
$\quad$ Permanent pacemaker insertion & $7(1.6)$ & $2(0.4)$ & .087 \\
$\quad$ Low cardiac output syndrome & $6(1.4)$ & $3(0.6)$ & .31 \\
$\quad$ Requirement for dialysis & $13(3.0)$ & $0(0)$ & $<.001$ \\
$\quad$ Mediastinitis & $0(0)$ & $1(0.2)$ & $>.99$ \\
$\quad$ Neurologic complication & $6(1.4)$ & $3(0.6)$ & .31 \\
Primary end point & $77(17.9)$ & $53(10.0)$ & $<.001$ \\
Death & $64(14.8)$ & $38(7.2)$ & $<.001$ \\
Tricuspid valve reoperation & $6(1.4)$ & $8(1.5)$ & $>.99$ \\
Admission due to heart failure & $16(3.7)$ & $10(1.9)$ & .11 \\
Other late complications & $37(8.6)$ & $48(9.1)$ & .78 \\
Stroke & $13(3.0)$ & $17(3.2)$ & .86 \\
Anticoagulation-related hemorrhages* & $18(4.2)$ & $24(4.5)$ & .78 \\
Reoperation, other causes $\dagger$ & $7(1.6)$ & $12(2.3)$ & .64 \\
Infective endocarditis & $0(0.0)$ & $2(0.4)$ & .51 \\
\hline
\end{tabular}

Data are presented as number (\%). *Hemorrhage related to prolonged prothrombin time requiring transfusion. †Reoperation due to valvular heart lesions other than tricuspid valve.

\section{RESULTS}

\section{Baseline Characteristics}

Preoperative baseline patient characteristics are summarized in Table 1. Patients in the repair group had higher clinical and echocardiographic risk factors than those in the control group as evidenced by older age $(P<.001)$, more history of previous cardiac surgery $(P<.001)$, higher prevalence of atrial fibrillation (AF) $(P<.001)$, more severe TR $(P<.001)$, and poorer $\operatorname{LVEF}(P<0.001)$.

Five hundred four patients $(52.6 \%)$ underwent MV surgery for mitral regurgitation, 311 patients $(32.4 \%)$ for mitral stenosis, and 144 patients $(15.0 \%)$ for mixed lesion in total cohort. There were no significant between-group differences according to the etiology of the MV disease $(P=.073)$ (Table 1). The Maze procedure was concomitantly performed in 194 patients $(45.0 \%)$ in the repair group and 185 patients $(35.0 \%)$ in the control group (Table 1$)$. MV repair was performed in 406 patients $(42.3 \%)$ in total cohort.

\section{Clinical Outcomes}

Perioperative results. Cardiopulmonary bypass (146.3 \pm 55.9 minutes vs $115.0 \pm 45.8$ minutes; $P<.001)$ and aortic cross-clamp $(95.9 \pm 35.9$ minutes vs $73.9 \pm 33.6$ minutes; $P<.001)$ times were significantly longer in the repair group than in the control group. The operative mortality rate was $1.0 \%(\mathrm{n}=10)$. There were no significant differences in early mortality $(1.6 \%$ vs $0.6 \% ; P=.12)$ or major morbidity rates $(15.5 \%$ vs $13.4 \% ; P=.36)$ (Table 2$)$.
TABLE 3. Unadjusted and adjusted hazard ratio (HR) and $\mathbf{9 5} \%$ confidence interval (CI) of clinical outcomes for tricuspid valve repair compared with nonrepair

\begin{tabular}{|c|c|c|c|c|c|c|}
\hline & \multicolumn{3}{|c|}{ Crude } & \multicolumn{3}{|c|}{ Adjusted } \\
\hline & HR & $95 \% \mathrm{CI}$ & $P$ & HR & $95 \%$ CI & $P$ \\
\hline Death & 1.76 & $1.17-2.65$ & .007 & 1.41 & $0.82-2.42$ & .22 \\
\hline TV reoperation & 0.74 & $0.24-2.24$ & .59 & 0.46 & $0.10-2.07$ & .31 \\
\hline $\mathrm{CHF}$ admission & 1.84 & $0.83-4.12$ & .14 & 1.12 & $0.37-3.36$ & .84 \\
\hline Primary outcome* & 1.66 & $1.16-2.38$ & .006 & 1.24 & $0.76-2.03$ & .39 \\
\hline $\begin{array}{l}\text { Composite outcome } \\
\text { (primary }+ \text { secondary } \\
\text { outcomes } \dagger \text { ) }\end{array}$ & 1.49 & $1.10-2.00$ & .01 & 1.19 & $0.79-1.80$ & .40 \\
\hline
\end{tabular}

$\overline{T V}$, Tricuspid valve; $C H F$, congestive heart failure; $H R$, hazard ratio; $C I$, clinical outcomes. *Composite of death, tricuspid reoperation, and readmission due to heart failure. $\dagger$ Composite of valve-related complications, including thromboembolic events, anticoagulation-related hemorrhage, and reoperation for valvular lesions other than tricuspid valve or infective endocarditis.

Primary and secondary end points. During a median clinical follow-up period of 64.8 months (range, 0.03203.6 months), there were 102 late deaths, 14 cases of TV reoperation, and 26 readmissions for CHF. There were no significant differences in the frequency of TV reoperation and re-admission for CHF between the groups; however, late deaths were more frequent in the repair group than in the control group $(14.8 \%$ vs $7.2 \% ; P<.001)$ (Table 2$)$. Both groups had similar risk for other late complications affected by valve surgery, such as stroke, significant hemorrhage related to anticoagulation, reoperation due to valvular heart lesions other than TV, or infective endocarditis.

The hazard of concomitant TV repair compared with nonrepair was estimated without adjustment and with adjustment (Table 3). After adjustment for baseline characteristics using a propensity score model, patients in the repair group had similar risk of death (hazard ratio [HR], 1.41; 95\% confidence interval [CI], 0.82-2.42; $P=.22$ ), readmission for CHF (HR, 1.12; 95\% CI, 0.37-3.36; $P=.84$ ), primary outcomes (HR, 1.24; 95\% CI, 0.76-2.03; $P=.39)$, and the composite of all adverse events (HR, 1.19; $95 \%$ CI, $0.79-1.80 ; P=.40$ ) as those in the control group. Although there was a trend for lower risk of TV reoperation in the repair group, it was not statistically significant (HR, $0.46 ; 95 \%$ CI, $0.10-2.07 ; P=.31$ ) (Table 3 and Figure 1). Independent risk factors for the primary end point. Multivariate Cox regression analysis was performed to determine the independent risk factors for the primary outcomes (Table 4). Age (HR, 1.04; 95\% CI, 1.03-1.06; $P<.001$ ), AF without a Maze procedure (HR, 1.66; 95\% CI, 1.05-2.63; $P=.030$ ), diabetes mellitus (HR, 2.08; 95\% CI, 1.21-3.57; $P=.008$ ), chronic renal failure (HR, 4.28; 95\% CI, 1.04-17.66; $P=.044$ ), poor LVEF (HR, $1.32 ; 95 \% \mathrm{CI}, 1.10-1.56 ; P=.003)$, and history of previous open heart surgery (HR, 2.52; 95\% CI, 1.26-5.05; $P=.009$ ) emerged as significant independent risk factors for the primary outcomes. 

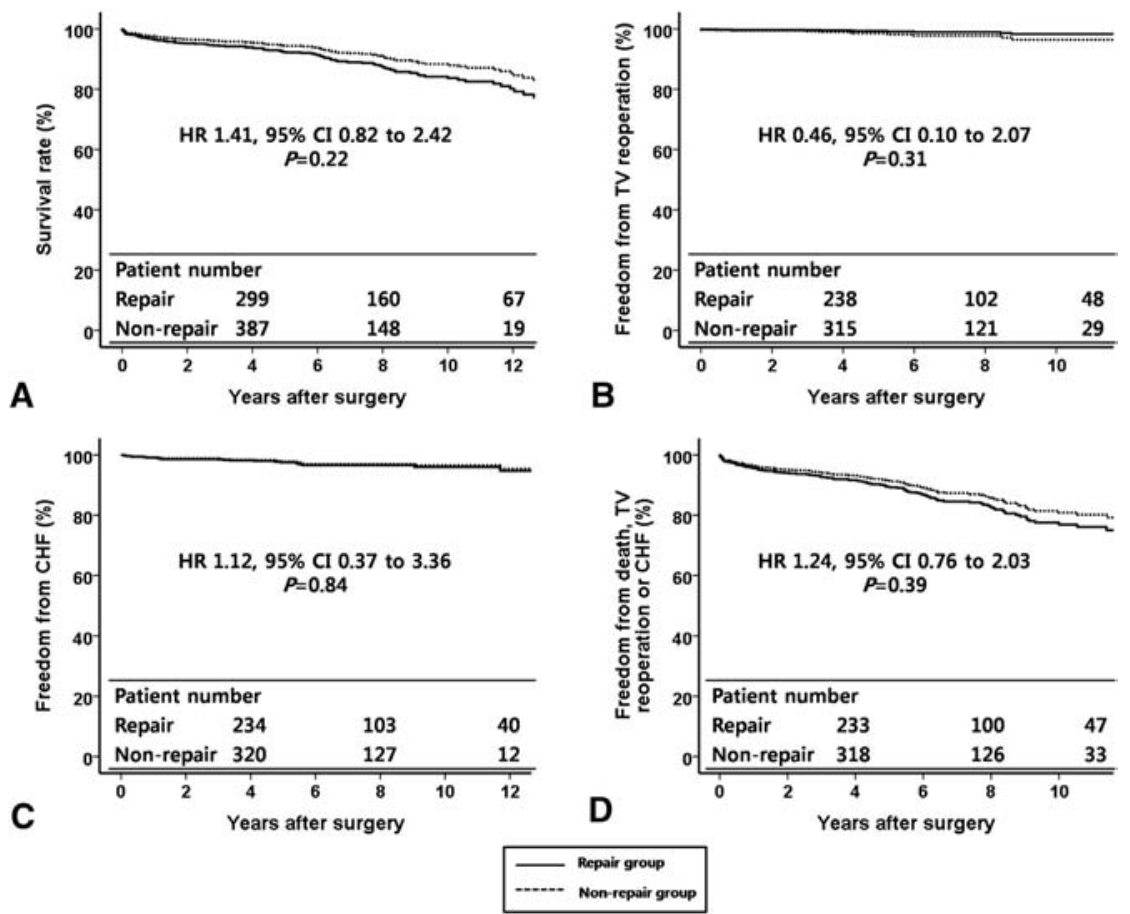

FIGURE 1. The cumulative incidence rates of clinical end points in the repair and control groups after adjustment. A, Overall survival. B, Freedom from tricuspid valve $(T V)$ reoperation. $\mathrm{C}$, Freedom from congestive heart failure $(\mathrm{CHF})$ requiring readmission. D, Freedom from the composite of death, TV reoperation, and CHF requiring readmission. HR, Hazard ratio; $C I$, confidence interval.

\section{Comparison of Echocardiographic Outcomes}

Between the 2 Groups: Propensity Score Matching

Of 939 survivors $>6$ months after surgery, 844 patients $(89.9 \%)$ had follow-up echocardiogram for $>6$ months. Median follow-up duration was $69.2 \pm 44.2$ months, with a range of 6.0 to 203.6 months. Propensity score matching for the 844 patients yielded 144 matched pairs of patients. In the matched cohort, there were no significant betweengroup differences for any baseline covariates (Table 5). Median follow-up durations were 68.1 months (range, 7.3-199.3 months) in the repair group and 64.6 months (range, 7.2-196.5 months) in the control group $(P=.16)$.

Preoperative and postoperative TR grades were compared between the 2 groups in the matched cohort

TABLE 4. Multivariate Cox regression analysis to identify independent risk factors for the composite of death, tricuspid valve reoperation, and congestive heart failure

\begin{tabular}{lccr}
\hline & $\begin{array}{c}\text { Hazard } \\
\text { ratio }\end{array}$ & $\begin{array}{c}\mathbf{9 5} \% \text { confidence } \\
\text { interval }\end{array}$ & $\boldsymbol{P}$ \\
\hline Age (y) & 1.04 & $1.03-1.06$ & $<.001$ \\
AF without Maze & 1.66 & $1.05-2.63$ & .030 \\
Diabetes mellitus & 2.08 & $1.21-3.57$ & .008 \\
Chronic renal failure & 4.28 & $1.04-17.66$ & .044 \\
LV ejection fraction (by 10\%) & 0.76 & $0.64-0.91$ & .003 \\
Redo surgery & 2.52 & $1.26-5.05$ & .009 \\
MICS & 0.57 & $0.29-1.10$ & .095 \\
\hline
\end{tabular}

$\overline{A F \text {, Atrial fibrillation; } L V \text {, left ventricular; } M I C S \text {, minimally invasive cardiac surgery. }}$ $(\mathrm{n}=288)$ (Figure 2). There were no between-group differences in preoperative TR grades $(P>.99)$ (Figure 2, $A$ ); however, comparing the severity of TR at the last followup, patients with greater than moderate TR were significantly less common in the repair group compared with those in the control group $(10.4 \%$ vs $13.9 \% ; P=.023)$ (Figure 2, B).

\section{DISCUSSION}

Several studies have shown that uncorrected significant functional TR after left heart valve surgery is associated with increased mortality and morbidity ${ }^{4,10-12}$ and decreased functional outcome. ${ }^{10,13-15}$ However, data are limited with regard to whether uncorrected functional TR will progress despite resolution of the left heart lesion responsible for overloading the right ventricle. Updated guidelines of the American College of Cardiology/American Heart Association regarding valve disease suggest that TV repair is beneficial for severe TR in patients with MV disease requiring MV surgery (Class I, level of evidence: B). ${ }^{5}$ According to these guidelines, however, less than severe TR in patients undergoing MV surgery is not a definite indication for tricuspid annuloplasty (Class IIb, level of evidence: C). The European Society of Cardiology guidelines on the management of valvular heart disease also state that severe TR in a patient undergoing left-sided valve surgery is the only definite indication for TV repair (Class I, level of evidence: C). ${ }^{6}$ 
TABLE 5. Baseline characteristics of propensity score matched groups

\begin{tabular}{|c|c|c|c|}
\hline & $\begin{array}{l}\text { Repair } \\
\text { group }\end{array}$ & $\begin{array}{l}\text { Nonrepair } \\
\text { group }\end{array}$ & $\boldsymbol{P}$ \\
\hline No. of patients & 144 & 144 & \\
\hline Age (y) & $50.5 \pm 13.6$ & $50.2 \pm 11.8$ & .79 \\
\hline Man & $54(37.5)$ & $64(44.4)$ & .27 \\
\hline Diabetes mellitus & $9(6.3)$ & $6(4.2)$ & .61 \\
\hline Hypertension & $18(12.5)$ & $19(13.2)$ & $>.99$ \\
\hline Chronic renal failure & $0(0.0)$ & $0(0.0)$ & $\mathrm{NC}$ \\
\hline Redo open heart surgery & $6(4.2)$ & $6(4.2)$ & $>.99$ \\
\hline Atrial fibrillation & $95(66.0)$ & $98(68.1)$ & .065 \\
\hline Maze procedure & $72(50.0)$ & $77(53.5)$ & .065 \\
\hline History of thromboembolic events & $9(6.3)$ & $5(3.5)$ & .42 \\
\hline Stroke & $8(5.6)$ & $4(2.8)$ & .39 \\
\hline Other thromboembolic events & $1(0.7)$ & $1(0.7)$ & $>.99$ \\
\hline \multicolumn{4}{|l|}{ Tricuspid regurgitation } \\
\hline Mild & $117(81.3)$ & $117(81.3)$ & $>.99$ \\
\hline Moderate & $27(18.8)$ & $27(18.8)$ & $>.99$ \\
\hline LV ejection fraction $(\%)$ & $56.5 \pm 9.2$ & $56.4 \pm 9.9$ & .93 \\
\hline LV end-systolic dimension (mm) & $39.1 \pm 7.4$ & $39.9 \pm 7.4$ & .33 \\
\hline LV end-diastolic dimension (mm) & $57.2 \pm 9.7$ & $58.0 \pm 9.7$ & .50 \\
\hline Left atrial dimension $(\mathrm{mm})$ & $59.1 \pm 12.3$ & $59.5 \pm 11.2$ & .81 \\
\hline $\begin{array}{l}\text { Trans TV pressure } \\
\text { gradient }(\mathrm{mm} \mathrm{Hg})\end{array}$ & $40.2 \pm 14.6$ & $39.5 \pm 17.4$ & .68 \\
\hline \multicolumn{4}{|l|}{ Surgery type } \\
\hline MVP & $67(46.5)$ & $66(45.8)$ & $>.99$ \\
\hline MVR & $77(53.5)$ & $78(54.2)$ & $>.99$ \\
\hline MICS & $40(27.8)$ & 34 (23.6) & .47 \\
\hline
\end{tabular}

Data are presented as mean \pm standard deviation or number (\%). $L V$, Left ventricular; $T V$, tricuspid valve; $M V P$, mitral valve repair; $M V R$, mitral valve replacement; $M I C S$, minimally invasive cardiac surgery.

Recently, as the significance of TR has been addressed, a few studies have reported on mild-to-moderate TR. Song and colleagues ${ }^{15}$ reported that $7.7 \%$ of untreated mild TR progressed to late significant TR despite successful left-sided valve surgery through a retrospective study involving 638 patients during a mean follow-up period of 64 months. Because late significant TR was associated with worse clinical outcomes, they suggested that aggressive surgical intervention may be considered in patients with risk factors for developing late significant TR. Another retrospective comparison of surgical and conservative treatment for mild-to-moderate functional TR showed that concomitant TV repair with MV repair or replacement decreased right ventricular diameter and the average grade of TR. ${ }^{16}$ Kim and colleagues ${ }^{17}$ reported a retrospective study of 236 patients with mild-to-moderate functional TR who underwent MV replacement for rheumatic MV disease. In their study, concomitant TV repair for mild-tomoderate functional TR was associated with better postoperative TV function.

Dreyfus and colleagues ${ }^{3}$ recommended that the TV annulus should be measured at the time of left heart valve surgery and tricuspid dilatation should be corrected regardless of the severity of TR because TV disease is correlated with tricuspid dilatation rather than the degree of TR. They measured the tricuspid annular diameter intraoperatively from the anteroseptal commissure to the anteroposterior commissure. Patients with a tricuspid annular dimension $\geq 70 \mathrm{~mm}$ underwent tricuspid annuloplasty, which improved functional status.

Yilmaz and colleagues ${ }^{18}$ analyzed changes in the degree of functional TR in 699 patients who underwent MV repair for degenerative MV disease. Their data demonstrated that the progression of TR in patients undergoing MV repair is unusual, and that coexistent TR did not affect late mortality. The authors emphasized the significance of preoperative comorbidities in the determination of clinical outcomes rather than the presence of functional TR. In agreement with their report, our study also showed that several preoperative factors and the performance of Maze procedure for AF had more clinical significance in the determination of overall outcomes than the concomitant TV repair.

In our study, concomitant TV repair was not associated with better clinical outcomes, but did result in better TR grades. These results are not much different from other retrospective studies, although the size of our study was larger and the disease entity was extended to entire MV disease. In other words, better TV function did not seem to affect longterm clinical outcomes in this study. Rather, several preoperative factors such as age, diabetes mellitus, chronic renal failure, LVEF, history of cardiac surgery, and the performance of Maze procedure for patients with AF seem to be more important in overall clinical outcomes. However, considering that it takes longer time for significant TR to affect heart function, compared with the clinical course of left sided valve disease; the clinical follow-up period of this study may not be long enough to verify the efficacy of concomitant TV repair.

\section{Limitations}

Our study was retrospective in nature and nonrandomized. Moreover, surgical indications and surgical techniques were not uniform among surgeons who did or did not perform concomitant TV repair. In the matched cohort, $81.3 \%$ of patients had mild TR and only $18.8 \%$ had moderate TR. Therefore, the study results may mainly represent those of patients with mild TR, and the conclusions on patients with moderate TR may not be as robust as for patients with mild TR. These limitations might have affected our results, although rigorous statistical adjustment was used for analysis. Echocardiographic values that are associated with the right heart, such as tricuspid annular dimension, TV tethering distance, and TV tethering area could not be routinely estimated, and right ventricular function was not quantified. The median follow-up period of this study was 64.8 months (ie, 5 years), which may not be long enough to interpret the effect of significant TR on clinical outcomes. 

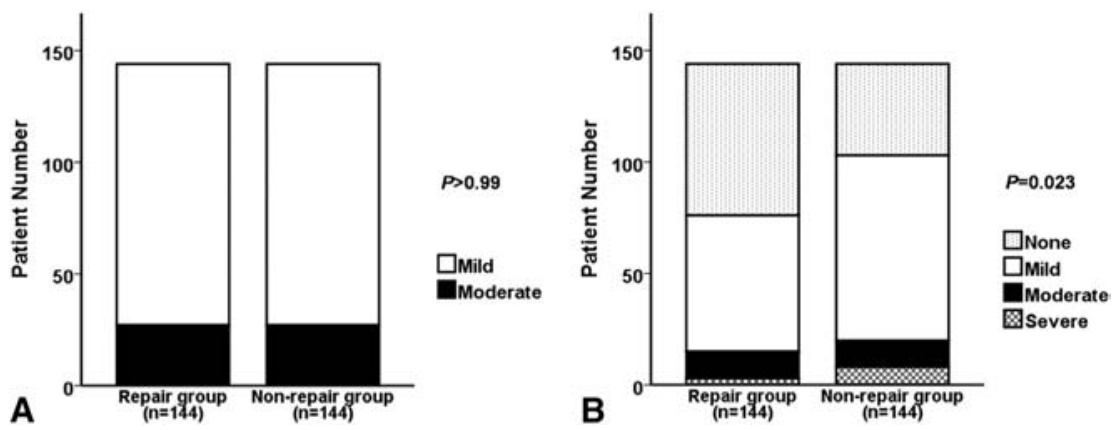

FIGURE 2. Comparison of the severity of tricuspid regurgitation between the groups using propensity score matching. A, Preoperative severity of tricuspid regurgitation. B, Postoperative severity of tricuspid regurgitation at the final follow-up.

\section{CONCLUSIONS}

The clinical benefit of concomitant TV repair for mild-tomoderate concomitant functional TR during MV surgery remains uncertain. Risk factors such as age, diabetes mellitus, chronic renal failure, poor LVEF, history of prior cardiac surgery, and concomitant Maze procedure for AF seem to be more important than TV repair on late clinical outcome. Concomitant TV repair cannot therefore be routinely recommended in this patient population at the time of $\mathrm{MV}$ repair or replacement.

\section{References}

1. Sagie A, Freitas N, Chen MH, Marshall JE, Weyman AE, Levine RA. Echocardiographic assessment of mitral stenosis and its associated valvular lesions in 205 patients and lack of association with mitral valve prolapse. J Am Soc Echocardiogr. 1997;10:141-8

2. Braunwald NS, Ross J Jr, Morrow AG. Conservative management of tricuspid regurgitation in patients undergoing mitral valve replacement. Circulation. 1967;35:I63-9.

3. Dreyfus GD, Corbi PJ, Chan KM, Bahrami T. Secondary tricuspid regurgitation or dilatation: which should be the criteria for surgical repair? Ann Thorac Surg. 2005;79:127-32.

4. Kuwaki K, Morishita K, Tsukamoto M, Abe T. Tricuspid valve surgery for functional tricuspid valve regurgitation associated with left-sided valvular disease. Eur J Cardiothorac Surg. 2001;20:577-82.

5. Bonow RO, Carabello BA, Chatterjee K, de Leon AC Jr, Faxon DP, Freed MD, et al. 2008 focused update incorporated into the ACC/AHA 2006 guidelines for the management of patients with valvular heart disease: a report of the American College of Cardiology/American Heart Association Task Force on Practice Guidelines (Writing Committee to revise the 1998 guidelines for the management of patients with valvular heart disease). JAm Coll Cardiol. 2008;52:e1-142.

6. Vahanian A, Baumgartner H, Bax J, Butchart E, Dion R, Filippatos G, et al. Guidelines on the management of valvular heart disease: the Task Force on the Management of Valvular Heart Disease of the European Society of Cardiology. Eur Heart J. 2007;28:230-68.
7. Gonzalez-Vilchez F, Zarauza J, Vazquez de Prada JA, Martín Durán R, Ruano J, Delgado C, et al. Assessment of tricuspid regurgitation by Doppler color flow imaging: angiographic correlation. Int J Cardiol. 1994;44: 275-83.

8. Gum PA, Thamilarasan M, Watanabe J, Blackstone EH, Lauer MS. Aspirin use and all-cause mortality among patients being evaluated for known or suspected coronary artery disease: a propensity analysis. JAMA. 2001;286: 1187-94.

9. Sagie A, Schwammenthal E, Newell JB, Harrell L, Joziatis TB, Weyman AE, et al. Significant tricuspid regurgitation is a marker for adverse outcome in patients undergoing percutaneous balloon mitral valvuloplasty. J Am Coll Cardiol. 1994;24:696-702.

10. McCarthy PM, Bhudia SK, Rajeswaran J, Hoercher KJ, Lytle BW, Cosgrove DM, et al. Tricuspid valve repair: durability and risk factors for failure. J Thorac Cardiovasc Surg. 2004;127:674-85.

11. Hornick P, Harris PA, Taylor KM. Tricuspid valve replacement subsequent to previous open heart surgery. J Heart Valve Dis. 1996;5:20-5.

12. Groves PH, Ikram S, Ingold U, Hall RJ. Tricuspid regurgitation following mitral valve replacement: an echocardiographic study. J Heart Valve Dis. 1993;2: 273-8.

13. Nath J, Foster E, Heidenreich PA. Impact of tricuspid regurgitation on long-term survival. J Am Coll Cardiol. 2004;43:405-9.

14. Groves PH, Lewis NP, Ikram S, Maire R, Hall RJ. Reduced exercise capacity in patients with tricuspid regurgitation after successful mitral valve replacement for rheumatic mitral valve disease. Br Heart J. 1991;66:295-301.

15. Song H, Kim MJ, Chung CH, Choo SJ, Song MG, Song JM, et al. Factors associated with development of late significant tricuspid regurgitation after successful left-sided valve surgery. Heart. 2009;95:931-6.

16. Smíd M, Cech J, Rokyta R, Roucka P, Hájek T. Mild to moderate functional tricuspid regurgitation: retrospective comparison of surgical and conservative treatment. Cardiol Res Pract. 2010;2010:143878.

17. Kim JB, Yoo DG, Kim GS, Song H, Jung SH, Choo SJ, et al. Mild-to-moderate functional tricuspid regurgitation in patients undergoing valve replacement for rheumatic mitral disease: the influence of tricuspid valve repair on clinical and echocardiographic outcomes. Heart. 2012;98:24-30.

18. Yilmaz O, Suri RM, Dearani JA, Sundt TM III, Daly RC, Burkhart HM, et al Functional tricuspid regurgitation at the time of mitral valve repair for degenerative leaflet prolapse: the case for a selective approach. $J$ Thorac Cardiovasc Surg. 2011;142:608-13. 